(RESEARCH ARTICLE)

\title{
Utilization of radiation monitoring devices among radio-diagnostic staff of secondary and tertiary hospitals in Jos, Nigeria: a comparative study
}

\author{
Ani Charles Chibunna ${ }^{1,{ }^{*}}$ and Zoakah Ayuba Ibrahim ${ }^{2}$ \\ ${ }^{1}$ Department of Radiology, Jos University Teaching Hospital/University of Jos, PMB 2067 Jos, 930001, Plateau State, \\ Nigeria \\ ${ }^{2}$ Department of Community Medicine, Jos University Teaching Hospital/ University of Jos, Plateau State, Nigeria
}

Publication history: Received on 11 February 2020; revised on 24 February 2020; accepted on 25 February 2020

Article DOI: https://doi.org/10.30574/wjarr.2020.5.2.0041

\begin{abstract}
Radio-diagnostic staff are expected to always and routinely adorn a form of radiation monitoring device to enable objective monitoring of the exposure to each individual with such monitoring aimed at checking any ill effects of radiation. This cross-sectional study aimed at comparing the utilization of radiation monitoring devices among radiodiagnostic staff was conducted in 2 tertiary hospitals and 2 secondary hospitals in Jos, Plateau State, Nigeria between August 2019 and October 2019. Consenting staff of radio-diagnostic departments of the 4 hospitals filled up a selfadministered questionnaire. Data were analyzed using Statistical Package for Social Sciences (SPSS) version 23. A total of 60 staff: $51(85 \%)$ in the tertiary, and $9(15 \%)$ in the secondary hospitals participated in the study. A positive attitude to the proper use of radiation monitoring device was found to be higher among staff in the tertiary hospitals $(44 / 51 ; 86.3 \%)$ compared to those in the secondary hospitals $(7 / 9 ; 77.8 \%) ; \chi 2=0.4332, p=0.510$. Statistically significant association was established between age of staff and attitude to use of the monitoring device in tertiary facilities: $\chi 2=9.379, \mathrm{p}=0.05$, and also between age of staff, years in service and years in the department and the practical usage of the radiation monitoring device among the staff of the secondary hospitals: $\chi 2=9.000, p=0.029$; $\chi 23.937, \mathrm{p}=0.047 ; \chi 23.937, \mathrm{p}=0.047$ respectively. The utilization of radiation monitoring devices among the radiodiagnostic staff in Jos was predominantly positive. Age of the staff, years in service as well as years in the present department were significant associations to utilization of radiation monitoring devices among staff across the two hospital categories.
\end{abstract}

Keywords: Utilization; Ionizing; Radiation; Secondary; Tertiary; Hospital

\section{Introduction}

The discovery of X-rays in 1895 by Wilhelm Conrad Roentgen which won him the Nobel Prize for Physics 6 years later shaped a revolution in the field of medicine [Revolvy portal, https://www.revolvy.com/page/Wilhelm-Röntgen, Last accessed on 3/3/2019]. During the following years, the inherent dangers in radiation were brought to the fore with such findings as skin erythema and radiation burn [Cancer Treatment Centers of America portal, https://www.cancercenter.com/integrative-care/radiation-burns, Last accessed on 3/3/2019]. Owing to the recognized harmful effects on experimental subjects and the health concern to staff and patients, changes in designs and various modifications in the production and use of X-rays had to be instituted for the safety of radiation staff and patients. Workers in a radiation department have an increased risk for radiation exposure than the general hospital population [1]. These group including Radiologists, Radiographers, Physicists, Biomedical Engineers, Darkroom Technicians, X-ray Assistants and Radiation Nurses also constitute the largest single group of workers occupationally exposed to artificial sources of radiation. Such artificial sources of radiation have also continued to vary and increase

\footnotetext{
${ }^{*}$ Corresponding author

E-mail address: dranicharles@yahoo.com
} 
over the years with miniaturization units like mobile x-ray and mobile CT-scan machines and multiplication units like multi-slice CT scanner [2].

Guidelines on the safety of workers handling patients for diagnostic X-ray were introduced for the first time in 1905 [3]. Among the guideline is the periodic and continual monitoring of staff and involved personnel by way of a monitoring device which is to be worn by all radiation workers. The International Commission on Radiological Protection (ICRP) emphasizes that the radiation exposure of patients and workers should be kept as low as reasonably achievable (ALARA principle) [4]. This should be the basis for all radiation protection measures in any radiation facility and is defined by justification, optimization and limitation of radiation to human subjects.

Compliance with regulatory or generally accepted radiation dose limits is necessary to prevent adverse deterministic effects of radiation which may occur with low level doses encountered in radio-diagnostic units. This compliance for each individual staff can only be measured by use of the personalized radiation monitoring device. Radiation safety for individual and general staff can thus be only guaranteed with the proper use of the monitoring device. Radiation protection measures can also be properly assessed if effective monitoring among staff is achieved, for instance, higher dose per individual may mean excessive of radiation from a point source or ineffective shielding in a room.

Various types of monitoring devices have been developed including film badge, pocket ionization chamber, thermoluminescent dosimeter (TLD), and instadose dosimeter. Such personnel monitoring devices should not only be available but be in appropriate use in the radiation facilities where this study was conducted. The study aims to determine and compare the attitude to the utilization of radiation monitoring devices among staff of radio-diagnostic departments of two tertiary hospitals - Jos University Teaching Hospital (JUTH) and Bingham University Teaching Hospital (BhUTH), and two secondary hospitals- Plateau Specialist Hospital (PSH) and Our Lady of Apostles Maternity (OLAM) all within Jos metropolis in Plateau State, North Central Nigeria.

\section{Material and methods}

JUTH, BhUTH, PSSH and OLAM are about 500, 180, 150 and 100 bedded hospitals respectively. These hospitals together harbor the largest concentration of radiation workers in Plateau State made up of staff of various cadre and units in the Radio-diagnostic departments of the 4 hospitals who were the target population for the study. The staff population of the Radio-diagnostic departments was about 75 in number, made up of 50 staff in JUTH, 10 staff in BhuTH, 10 staff in PSSH and 5 staff in OLAM.

The sample size was determined using the formula for comparison of proportions when conducting a comparative cross sectional study with the minimum sample size calculated to be about 32 for each group. However, total sampling was applied in view of the small sample size and all available and willing staff of radio-diagnostic departments in the named hospitals (totaling 60) participated in the study.

An anonymous, semi-structured, self-administered questionnaire was designed and validated following review of templates of previous validated studies $[5,6]$. The objectives of the study were explained to the participants before distribution of the questionnaire. The questionnaire included parts comprising questions about the demographics of subjects including their educational qualification, place of work and years in service, as well as parts on questions on attitude to proper use of radiation monitoring devices and practical use of the monitoring device among the staff. Responses to the questions on attitude to use of radiation monitoring devices were to be provided on a Likert-style scale in which the respondents were to select and tick only one box. The scale ranged from "Agree Strongly" (AS), "Agree" (A), "Not Certain" (NC), "Disagree" (D), and "Disagree Strongly" (DA) while responses to practical use of the monitoring device were to be supplied in form of short fill-ups to blank spaces provided as addendum at the end of the questions.

All filled questionnaire were retrieved from the various Radio-diagnostic departments. The responses were scored and graded. The points were awarded for ticked boxes as AS-5; A-4; NC-3; D-2; DS-1, for appropriateness of the responses starting from the left and AS-1; A-2; NC-3; D-4; DA-5, for appropriateness of the responses starting from the right. No response attracted 0 point. This gives a minimum score of ' 0 ' and a maximum score of ' 25 ' points. The participants that scored 18points (72\%) and above were considered as having 'positive' attitude, while those that scored less than 18 were graded as having 'negative' attitude.

Data analysis was performed using software SPSS version 23. Definite variables are shown as percentages and frequencies and results were presented in Tables. All levels of significance were set at $\mathrm{p}<0.05$. 
Ethical approval was obtained from the Ethical boards of all the included hospitals.

\section{Results}

A total of 60 staff of Radio-diagnostic departments of the involved hospitals participated in the study. These are made up of $47(78.3 \%)$ males and $13(21.7 \%)$ females. Fifty one $(85 \%)$ of the participants were staff in the tertiary hospitals (JUTH 46; BhUTH 5) while 9 (15\%) were in the secondary hospitals (PSSH 6; OLAM 3).

Table 1 Socio-demographic Characteristics of Respondents

\begin{tabular}{|c|c|c|c|c|c|}
\hline \multirow[t]{2}{*}{ Socio-demographics } & \multicolumn{2}{|c|}{ Health Facility } & \multirow{2}{*}{$\begin{array}{l}\text { Total } \\
(\%)\end{array}$} & \multirow[t]{2}{*}{$\mathrm{X}^{2}$} & \multirow[t]{2}{*}{ P - Value } \\
\hline & Secondary & Tertiary & & & \\
\hline \multicolumn{6}{|l|}{ Age (Years): } \\
\hline $21-30$ & 1 & 16 & $17(28.3)$ & 5.2108 & 0.266 \\
\hline $31-40$ & 1 & 14 & $15(25.0)$ & & \\
\hline $41-50$ & 4 & 14 & $18(30.0)$ & & \\
\hline $51-60$ & 3 & 6 & $9(15.0)$ & & \\
\hline$>60$ & 0 & 1 & $1(1.7)$ & & \\
\hline \multicolumn{6}{|l|}{ Gender: } \\
\hline Female & 3 & 10 & $13(21.7)$ & 0.8491 & 0.357 \\
\hline Male & 6 & 41 & $47(78.3)$ & & \\
\hline \multicolumn{6}{|l|}{ Qualification: } \\
\hline SSCE & 1 & 2 & $3(5.0)$ & 14.1363 & $0.049^{*}$ \\
\hline Technician & 3 & 4 & 7 (11.7) & & \\
\hline OND & 4 & 8 & $12((20.0)$ & & \\
\hline Degree/HND & 1 & 19 & $20(33.3)$ & & \\
\hline MBBS & 0 & 12 & $12(20.0)$ & & \\
\hline Fellowship & 0 & 6 & $6(10.0)$ & & \\
\hline \multicolumn{6}{|l|}{ Professional Cadre: } \\
\hline X-ray Assistant & 4 & 2 & $6(10.0)$ & 30.2148 & $0.000^{*}$ \\
\hline Darkroom Technician & 2 & 12 & $14(23.3)$ & & \\
\hline Physicist & 0 & 3 & $3(5.0)$ & & \\
\hline Resident Doctor & 0 & 8 & $8(13.3)$ & & \\
\hline Intern-Radiographer & 0 & 18 & $18(30.0)$ & & \\
\hline Radiographer & 3 & 1 & $4(6.7)$ & & \\
\hline Consultant & 0 & 7 & 7 (11.7) & & \\
\hline \multicolumn{6}{|l|}{ Years in Service: } \\
\hline$<10$ & 2 & 31 & $33(55.0)$ & 4.5963 & $0.032^{*}$ \\
\hline$\geq 10$ & 7 & 20 & $27(45.0)$ & & \\
\hline \multicolumn{6}{|l|}{ Years in Department: } \\
\hline$<10$ & 2 & 37 & $39(65.0)$ & 8.5168 & $0.004^{*}$ \\
\hline$\geq 10$ & 7 & 14 & $21(35.0)$ & & \\
\hline
\end{tabular}


Mean age: $39 \pm 11.2$ years

The age of the participants ranged from 24 years to 57 years with a mean age of $39 \pm 11.2$ years. There were more respondents in their fifth decade in the secondary hospitals $(4 / 9 ; 44.4 \%)$, while the modal age group of the respondents in the tertiary health facilities was the third decade $(16 / 51 ; 31.4 \%)$. More staff with years in service of less than 10 years participated in the study (33; 55\%) with most in this category found working in the tertiary hospitals. Those with less than 10 year stay in the present department were also found more in the tertiary centers (37; 61.7\%). The highest educational qualification among respondents in the secondary hospitals was Higher Diploma while it was a Post graduate Medical Fellowship in the tertiary hospitals. The highest cadre staff in the secondary hospitals were the Radiographers $(3 ; 33.3 \%)$ and the highest cadre staff in the tertiary hospitals were the Consultants $(7 ; 13.7 \%)$ (Table 1$)$

There was a noted difference in academic qualification and professional cadre between staff of secondary and tertiary health facilities, significant at 5\%. Significant difference was also seen in the number of years in service and years spent in the present department between the two hospital categories, with more of the staff serving and staying longer than 10 years found in the secondary hospitals (Table 1).

Majority of the staff who participated in the study $(51 ; 85.0 \%)$ showed a positive attitude to the proper use of radiation monitoring devices. The proportion of participants with positive attitude to the proper use of radiation monitoring device was found to be higher among staff in the tertiary hospitals $(44 / 51 ; 86.3 \%)$ compared to those in the secondary hospitals $(7 / 9 ; 77.8 \%)$. The difference between staff in the two hospital categories was not however statistically significant: $\chi^{2}=0.4332, \mathrm{p}=0.510$ (Table 2 ).

Table 2 Attitude to Use of Radiation Monitoring Device

\begin{tabular}{llllll}
\hline \multirow{2}{*}{$\begin{array}{l}\text { Attitude to use of Radiation } \\
\text { Monitoring Device }\end{array}$} & Health Facility & \multicolumn{2}{c}{ Total (\%) } & X2 & P-value \\
\cline { 2 - 5 } & Secondary & Tertiary & & \\
\hline Negative & 2 & 7 & $9(15.0)$ & 0.4332 & 0.510 \\
Positive & 7 & 44 & $51(85.0)$ & & \\
Total & 9 & 51 & $60(100)$ & \\
\hline
\end{tabular}

There was an association found between age of the staff in the tertiary facilities and attitude to use of the device, statistically significant at 5\%: $\chi^{2}=9.379, p=0.05$ (Table 3 ).

Statistically significant association was also established between age of staff, years in service and years in the department and the practical usage of the radiation monitoring device among the staff of the secondary hospitals: $\chi^{2}=$ 9.000, $\mathrm{p}=0.029 ; \chi^{2} 3.937, \mathrm{p}=0.047 ; \chi^{2} 3.937, \mathrm{p}=0.047$ respectively(Table 4 ).

While majority of the staff in the tertiary hospitals $(48 ; 94.1 \%)$ had been issued a personal radiation monitoring device, more than half of the staff in the secondary hospitals (5; 55.6\%) indicated that they did not have any monitoring device. Of those that possess a monitoring device, $28(58.3 \%)$ in the tertiary and $1(25 \%)$ in the secondary counterpart had practically worn their personal monitoring device in the previous 24 hours. This difference was found to be statistically significant: $\chi^{2}=5.8745, p=0.015$ (Table 5). 
Table 3 Association between Socio-demographics and Attitude to Use of Radiation Monitoring Device in Secondary and Tertiary Health Facilities

\begin{tabular}{|c|c|c|c|c|c|c|c|c|c|c|}
\hline \multirow{3}{*}{$\begin{array}{l}\text { Socio- } \\
\text { demographics }\end{array}$} & \multicolumn{5}{|c|}{ Secondary } & \multicolumn{5}{|c|}{ Tertiary } \\
\hline & \multicolumn{2}{|c|}{ Attitude } & \multirow[t]{2}{*}{ Total } & \multirow[t]{2}{*}{$\mathrm{X}^{2}$} & \multirow{2}{*}{$\begin{array}{l}P \\
\text { Value }\end{array}$} & \multicolumn{2}{|c|}{ Attitude } & \multirow[t]{2}{*}{ Total } & \multirow[t]{2}{*}{$\mathrm{X}^{2}$} & \multirow{2}{*}{$\begin{array}{l}P \\
\text { Value }\end{array}$} \\
\hline & 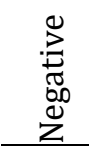 & 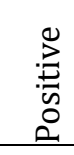 & & & & 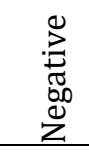 & $\begin{array}{l}0 \\
: \\
0 \\
0 \\
0\end{array}$ & & & \\
\hline \multicolumn{11}{|l|}{ Age (Years): } \\
\hline $21-30$ & 0 & 1 & 1 & 0.803 & 0.849 & 0 & 16 & 16 & 9.379 & $0.05^{*}$ \\
\hline $31-40$ & 0 & 1 & 1 & & & 2 & 12 & 14 & & \\
\hline $41-50$ & 1 & 3 & 4 & & & 2 & 12 & 14 & & \\
\hline $51-60$ & 1 & 2 & 3 & & & 3 & 3 & 6 & & \\
\hline$>60$ & 0 & 0 & 0 & & & 0 & 1 & 1 & & \\
\hline \multicolumn{11}{|l|}{ Gender: } \\
\hline Female & 1 & 2 & 3 & 0.321 & 0.571 & 1 & 9 & 10 & 0.145 & 0.703 \\
\hline Male & 1 & 5 & 6 & & & 6 & 35 & 41 & & \\
\hline \multicolumn{11}{|l|}{ Qualification: } \\
\hline SSCE & 1 & 0 & 1 & 5.142 & 0.162 & 1 & 1 & 2 & 7.685 & 0.361 \\
\hline Technician & 1 & 2 & 3 & & & 0 & 4 & 4 & & \\
\hline Diploma & 0 & 4 & 4 & & & 2 & 6 & 8 & & \\
\hline Degree/HND & 0 & 1 & 1 & & & 2 & 17 & 19 & & \\
\hline MBBS/MSc & 0 & 0 & 0 & & & 2 & 10 & 12 & & \\
\hline Fellowship & 0 & 0 & 0 & & & 0 & 6 & 6 & & \\
\hline \multicolumn{11}{|l|}{ Pro Cadre: } \\
\hline X-ray Assistant & 1 & 3 & 4 & 1.767 & 0.413 & 0 & 2 & 2 & 8.1895 & 0.225 \\
\hline Darkroom Tech & 1 & 1 & 2 & & & 3 & 9 & 12 & & \\
\hline Physicist & 0 & 0 & 0 & & & 0 & 3 & 3 & & \\
\hline Resident & 0 & 0 & 0 & & & 3 & 5 & 8 & & \\
\hline Intern & 0 & 0 & 0 & & & 1 & 17 & 18 & & \\
\hline Radiographer & 0 & 3 & 3 & & & 0 & 1 & 1 & & \\
\hline Consultant & 0 & 0 & 0 & & & 0 & 7 & 7 & & \\
\hline \multicolumn{11}{|l|}{ Years in Service: } \\
\hline$<10$ & 0 & 2 & 2 & 0.734 & 0.391 & 2 & 29 & 31 & 3.532 & 0.06 \\
\hline$\geq 10$ & 2 & 5 & 7 & & & 5 & 15 & 20 & & \\
\hline \multicolumn{11}{|l|}{ Years in Dept: } \\
\hline$<10$ & 0 & 2 & 2 & 0.734 & 0.391 & 4 & 33 & 37 & 0.967 & 0.325 \\
\hline$\geq 10$ & 2 & 5 & 7 & & & 3 & 11 & 14 & & \\
\hline
\end{tabular}


Table 4 Association between Socio-demographics and Practical Use of Monitoring Device

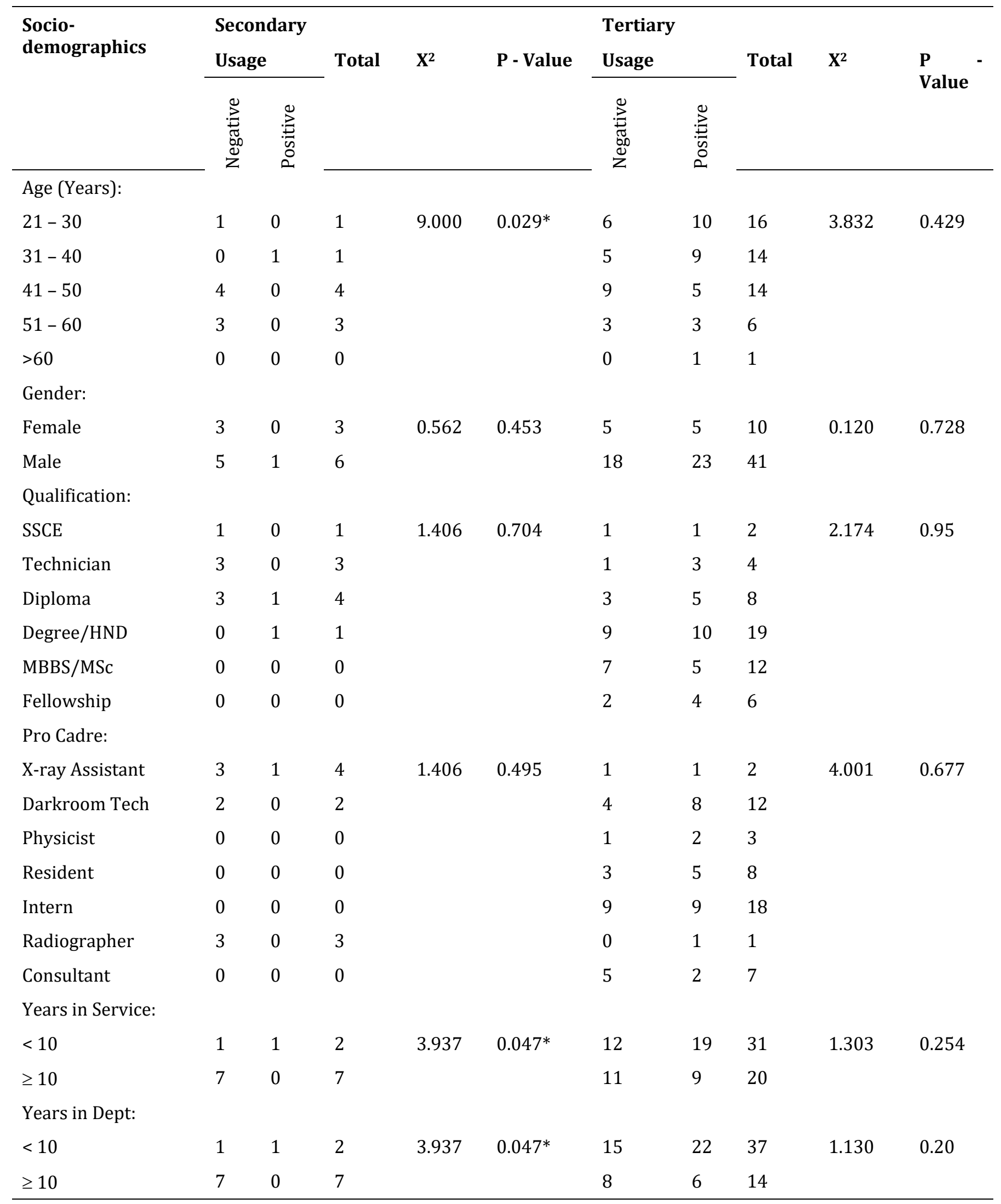


Table 5 Practical Use of Radiation Monitoring Device in the past 24 hours.

\begin{tabular}{llllll}
\hline \multirow{2}{*}{$\begin{array}{l}\text { Use of Radiation Monitoring } \\
\text { Device in the past 24 hours }\end{array}$} & \multicolumn{2}{l}{ Health Facility } & Total (\%) & X2 & P-value \\
\cline { 2 - 4 } & \multicolumn{2}{l}{ Secondary } & Tertiary & & \\
\hline No & 8 & 23 & $31(51.7)$ & 5.8745 & $0.015^{*}$ \\
Yes & 1 & 28 & $29(48.3)$ & & \\
Total & 9 & 51 & $60(100)$ & & \\
\hline
\end{tabular}

Number of issued Radiation Monitoring Device in Secondary Hospitals=4 (44.4\%)

Number of issued Radiation Monitoring Device in Tertiary Hospitals = 48 (94.1\%)

\section{Discussion}

There were much more staff participants in the tertiary health institutions than in the secondary counterparts $(51$ and 9 respectively). This apparently relates to the employer capacity in our setting. While the two tertiary institutions are government owned and funded, the two secondary hospitals are privately owned and funded. Jos University Teaching Hospital (JUTH), a Federal Government parastatal, alone, provided 46 (76.7\%) of the respondents in the study. The import of this however is that limited hands are left to render middle level radio-diagnostic services to the teeming population of patients expected in the secondary hospitals with the attendant heightening of the radiation related health risks and hazards to the few staff.

The mean age of the respondents in the study was $39 \pm 11.2$ years with a range of 24 to 67 years, both extremes being associated with the tertiary health facilities. The presence of younger staff participants who were engaged in internship programs and also of the senior cadre staff saddled with the teaching and training that go on in these institutions account for this.

Staff who have spent more than 10 years both in service and in stay in the present department were found to be more in the secondary hospitals than for tertiary hospitals (Table 1). This again corroborates the comparative youthfulness of the staff population in the tertiary hospitals and the transitional characteristics, with an appreciable number of staff in this training centers spending between one year and six years for their internship and residency programs. The more permanent nature of the engagement in the secondary hospitals should spur continuous improvement in knowledge and risk management measures by staff of radio-diagnostic departments.

The highest cadre of staff in the secondary hospitals were the Radiographers $(3 ; 33.3 \%)$ while the highest cadre of staff in the tertiary centers were the Consultants $(7 ; 13.7 \%)$. Other cadre of staff that were found in the tertiary hospitals but not in the secondary centers include the Resident Doctors and the Medical Physicists. The compliment of staff of various cadres in the tertiary hospitals should ostensibly translate to better integration and quality in service in the radio-diagnostic units including projection and adherence to set rules in radiation protection. This may however not be the case as other befuddling factors may play out in our limited resource setting.

Majority of the staff who participated in this study showed a positive attitude to the proper use of radiation monitoring devices with the proportion of those with positive attitude to the proper use of the monitoring device found to be higher, albeit insignificant, among staff in the tertiary hospitals compared to those in the secondary hospitals (Table 2).

Monitoring devices are very important in radiation protection and should be worn always by all staff in the department, under the protective lead apron, and above waist level (for the staff that put on the lead apron while working in the imaging rooms or controlled areas). The essence of dose monitoring for all staff is also to assist in picking up radiation leakages beyond the controlled area hence ensuring safety for staff, patients and their accompanying relations. Many studies have shown that the attitude and practice of radiation monitoring is not commensurate with the good knowledge possessed by staff of radiation departments $[7,8]$. The reverse is true of the findings in a study by Mojiri et al [9] which reported high awareness of the necessity of application of monitoring device among the participants. Following an assessment of radiation protection practices among 40 radiographers in radio-diagnostic units of 4 tertiary hospitals in Lagos, Nigeria, Eze et al [10] concluded that the good knowledge of the hazards of radiation had Also, in a study on the assessment of radiation protection practices among university 
students at Buraydah, Saudi Arabia, Al-Sayyari and Kalagi [5] found that all of the participants who were University undergraduate internship students from Radiologic Technology department followed the radiation safety principle properly.

While no association was found in the secondary hospitals with respect to attitude to proper use of the radiation monitoring device, an association was found between age of the staff in the tertiary facilities and attitude to use of the device, statistically significant at 5\% (Table 3). Positive attitude to use of the monitoring device was found more among the younger age groups in the tertiary hospitals comprising mostly the interns and the resident doctors who have a tenured stay and hence retain the least work experience in the department. This finding agrees with that of a questionnaire based KAP study by Rahman et al [11] which actually showed that the number of correct answers in those with more than 10 years' experience in contrast to those with less 10 years' experience was 45\% vs. 56\%, respectively. Other authors $[12,13]$ have reported the converse however, as it would be usually expected, that with age while working in the department comes experience enough to stimulate positive attitude to proper use of the radiation monitoring devices.

Statistically significant association was also found between the age of staff, years in service and years in the department with the practical usage of the radiation monitoring device among the staff of the secondary hospitals (Table 4) with the relatively younger staff and those with less than ten years' experience demonstrating better usage than the older, apparently more experienced staff. This finding lends support to what is already discussed above. It is indeed possible that some assume a 'know-it-all' posture or lose their guard as they age in service assuming that only the younger ones should be concerned, since by this time they perhaps less frequently enter the controlled areas by their schedule of duty.

Among the respondents, majority in the tertiary hospitals (48; 94.1\%) had been issued a personal radiation monitoring device. However, more than half in the secondary hospitals $(5 ; 55.6 \%)$ indicated that they do not have any monitoring device. Of those that possess a monitoring device, $28(58.3 \%)$ in the tertiary and $1(25 \%)$ in the secondary counterpart had practically worn their personal monitoring device in the previous 24 hours. This difference was found to be statistically significant: $\chi 2=5.8745, p=0.015$ (Table 5). The main stated reason for not adorning a radiation monitoring device was forgetfulness.

Le Heron et al [14] found out that the radiation workers do not always put on their monitoring devices and decried the low compliance of the involved staff. The low level of compliance to proper adornment of the radiation monitoring device implies poor record of absorbed dose per individual staff and unnecessary exposure to the risks associated with ionizing radiation. Okaro et al [15] found that personnel radiation monitoring in South Eastern Nigeria was abysmally poor

In a study involving 413 radiation workers, it was noticed that while 94.9 percent of the participants had their own personal dosimeter, 55 percent submitted that the use of their personal dosimeter in a radiation environment was irregular; and76.3 percent applied their personal dosimeter in wrong places. The poor practice was attributed more to the participants having less years of experience as radiation workers than to their knowledge of radiation protection principles [16]. The study by Al-Sayyari and Kalagi [5] also established that the internship students applied the thermoluminiscent dosimeter (TLD) monitoring device quite properly. This was attributed to quality of training program delivered by the staff at the University which enabled the student technologists develop a passion for radiation protection.

\section{Conclusion}

The study showed that the utilization of radiation monitoring devices among the radio-diagnostic staff of secondary and tertiary hospitals in Jos was largely positive both in attitude to proper usage and in the practical handling of such monitoring devices. The proportion of participants with positive attitude to handling of monitoring devices was found to be higher among staff in the tertiary hospitals when compared to those in the secondary hospitals. The difference between the two hospital groups was however not statistically significant. The age of the staff, years in service as well as years in the present department were established as significant associations to utilization of radiation monitoring devices among staff across the two hospital categories. 


\section{Compliance with ethical standards}

\section{Acknowledgments}

The co-operation of the heads of radio-diagnostic departments of Jos University Teaching Hospital, Bingham University Teaching Hospital, Plateau Specialist Hospital and Our Lady of Apostle Maternity, all in Jos, is hereby well acknowledged.

\section{Disclosure of conflict of interest}

No disclosure of any conflicts of interest.

\section{Statement of ethical approval}

Ethical Approval was sought and obtained from the Ethical boards of all the involved 4 hospitals.

\section{Statement of informed consent}

Informed consent was obtained from all individual participants involved in the study.

\section{References}

[1] International Atomic Energy Agency (2018). Radiological Protection for Medical Exposure to Ionizing Radiation, Safety Guide. No SSG-46, 53-123.

[2] Abrantes A, Rebelo C, Sousa P, Rodrigues S, Almeida RP, Pinheiro J, Aevedo K and Ribeiro L. (2017). Scatter radiation exposure during mobile x-ray examination. Health Management, 17(1).

[3] Calder J. (2001). The history of radiology in Scotland 1896-2000.

[4] International Commission on Radiological Protection. (2007). The 2007 recommendations of the ICRP. ICRP Publication 103, Oxford: Pergamon Press, Oxford, 1-4.

[5] Al-Sayyari AS and Kalagi S. (2018). Assessment of radiation protection practices among university students, Buraydah, Saudi Arabia. IOSR Journal of Dental and Medical Sciences, 17 (3), 71-77.

[6] Awosan KJ, Ibrahim MTO, Saidu SA, Ma'aji SM, Danfulani M, Yunusa EU, Ikhuenbor DB and Ige TA. (2016). Knowledge of radiation hazards, radiation protection practices and clinical profile of health workers in a teaching hospital in northern Nigeria. Journal of Clinical and Diagnostic Research, 10(8), LC07-LC12.

[7] Eze KC, Nzotta CC, Marchie TT, Okegbunam B and Eze TE. (2011). The state of occupational radiation protection and monitoring in public and private x-ray facilities in Edo state, Nigeria. Nigerian Journal of Clinical Practice, 14 (3), 308-310.

[8] Famurewa OC, Ayoola O0, Ogunsemoyin AO and Onayade AA. (2013). Radiation protection and dose awareness among doctors in a Nigerian teaching hospital: a preliminary study. West African Journal of Radiology, 20, 3740.

[9] Mojiri M and Moghimbeigi A. (2011).Awareness and attitude of radiographers towards radiation protection. Journal of Paramedical Sciences, 2 (4), 02-05.

[10] Eze CU, Abonyi LC, Njoku L, Irurhe NK and Olowu O. (2013).Assessment of radiation protection among radiographers in Lagos, Nigeria. Nigerian Medical Journal, 54(6), 386-391.

[11] Rahman N, Dhakam S, Shafqut A, Qadir S and Tipoo FA. (2008). Knowledge and practice of radiation safety among invasive cardiologists. Journal of Pakistan Medical Association, 58(3), 119-122.

[12] Alzubaidi MA, al Mutairi HH, Alkalel SH, Al Abdullah HAS, Albakri IA and Alqahtani SFA. (2017). Assessment of knowledge and attitude of nurses towards ionizing radiation during radiography in Jeddah City. The Egyptian Journal of Hospital Medicine, 69 (7), 2906-2909.

[13] Shabani F, Hasanzadeh H, Emadi A, Mirmohammadkhani M, Bitarafan-Rajabi A, Abedelahi A et al. (2018). Radiation protection, knowledge, attitude and practice (KAP) in interventional radiology. Oman Medical Journal, 33 (2), 141-147. 
[14] Le Heron J, Padovani R, Smith I and Czarwinski R. (2010). Radiation protection of medical staff. European Journal of Radiology, 76, 20-23.

[15] Okaro AO, Ohagwu CC and Njoku J. (2010). Evaluation of personnel radiation monitoring in radio-diagnostic centres in south eastern Nigeria. African Journal of Basic \& Applied Sciences, 2(1-2), 49-53.

[16] Alavi SS, Dabbagh ST, Abbasi M and Mehrdad R. (2017). Medical radiation workers' knowledge, attitude, and practice to protect themselves against ionizing radiation in Tehran Province, Iran. Journal of Education and Health Promotion, 6, 58.

\section{How to cite this article}

Ani CC and Zoakah AI. (2020). Utilization of radiation monitoring devices among radio-diagnostic staff of secondary and tertiary hospitals in Jos, Nigeria: a comparative study. World Journal of Advanced Research and Reviews, 5(2), 146-155. 